1 Local anaesthesia as a distinct comparator versus conscious sedation and

2 general anaesthesia in endovascular stroke treatment: a systematic review

\title{
and meta-analysis
}

4 Waleed Butt ${ }^{1 * \#}$, Permesh Singh Dhillon ${ }^{1,2 \#}$, Anna Podlasek ${ }^{2}$, Luqman Malik ${ }^{1}$, Sujit Nair ${ }^{1}$, 5 David Hewson $^{3}$, Timothy J England ${ }^{4,5}$, Robert Lenthall ${ }^{1}$, Norman McConachie ${ }^{1}$,

6

7 Affiliations

8 1. Interventional Neuroradiology, Queens Medical Centre, Nottingham University Hospitals NHS 9 Trust, Nottingham, United Kingdom.

10 2. NIHR Nottingham BRC, University of Nottingham, Nottingham, United Kingdom.

11 3. Anaesthesia and Critical Care Research Group, Division of Clinical Neuroscience, School of 12 Medicine, University of Nottingham, Nottingham, United Kingdom.

4. Vascular Medicine, Division of Medical Sciences and GEM, School of Medicine, University of 14 Nottingham, Derby, United Kingdom.

5. University Hospitals of Derby and Burton NHS Foundation Trust, Derby, United Kingdom

*Correspondence to: Waleed Butt; mohammad.butt2@nuh.nhs.uk Tel: 01159249924

\#Both authors contributed equally

19 Competing interests, Disclosures and Funding: None declared

20 Tables $=2$, Figures $=2$, Supplementary Figures $=6$

21 Abbreviations: EVT = Endovascular treatment, AIS = acute ischaemic stroke, LA = local 22 anaesthesia, $\mathrm{CS}=$ conscious sedation, $\mathrm{GA}=$ general anaesthesia, $\mathrm{mRS}=$ modified Rankin

23 Scale, TICI = thrombolysis in cerebral infarction, NIHSS = National Institutes of Health

24 Stroke Scale 
Background: The optimal anaesthetic modality for endovascular treatment (EVT) in acute ischaemic stroke (AIS) is undetermined. Comparisons of general anaesthesia (GA) with composite non-GA cohorts of conscious sedation (CS) and local anaesthesia (LA) without sedation have provided conflicting results. There has been emerging interest in assessing whether LA alone may be associated with improved outcomes. We conducted a systematicreview and meta-analysis to evaluate clinical and procedural outcomes comparing LA to CS and GA.

Methods: We reviewed the literature for studies reporting outcome variables in LA versus CS and LA versus GA comparisons. The primary outcome was 90-day good functional outcome (modified Rankin Scale $(\mathrm{mRS} \leq 2)$. Secondary outcomes included mortality, symptomatic intracerebral haemorrhage, excellent functional outcome $(\mathrm{mRS} \leq 1)$, successful reperfusion (thrombolysis in cerebral infarction $(\mathrm{TICI})>2 \mathrm{~b}$ ), procedural time metrics and procedural complications. Random effects meta-analysis was performed on unadjusted and adjusted data.

Results: Eight non-randomised studies of 7797 patients (2797 LA, 2218 CS, 2782 GA) were identified. In the LA versus GA comparison, no statistical differences were found in unadjusted analyses for 90 -day good functional outcome or mortality $(\mathrm{OR}=1.22,95 \% \mathrm{CI}$ $0.84-1.76, \mathrm{p}=0.3$ and $\mathrm{OR}=0.83,95 \% \mathrm{CI} 0.64-1.07, \mathrm{p}=0.15$ respectively) or in the LA versus CS comparison $(\mathrm{OR}=1.14,95 \% \mathrm{CI} 0.76-1.71, \mathrm{p}=0.53$ and $\mathrm{OR}=0.88,95 \% \mathrm{CI}$ 0.62-1.24, $\mathrm{p}=0.47$ respectively). There was a tendency towards achieving excellent functional outcome

$51(\mathrm{mRS} \leq 1)$ in the LA group versus GA $\left(\mathrm{OR}=1.44,95 \% \mathrm{CI} 1.00-2.08, \mathrm{p}=0.05, \mathrm{I}^{2}=70 \%\right)$. 
52 Analysis of adjusted data demonstrated a tendency towards higher odds of death at 90 days in 53 GA versus LA $\left(\mathrm{OR}=1.24,95 \% \mathrm{CI} 1.00-1.54, \mathrm{p}=0.05 \mathrm{I}^{2}=0 \%\right)$.

54

55 Conclusion: LA without sedation was not significantly superior to CS or GA in improving 56 outcomes when performing EVT for AIS. However, quality of included studies impairs

57 interpretation and inclusion of a LA arm in future well-designed multi-centre randomised 58 controlled trials is warranted.

59

60

61 
64 Endovascular treatment (EVT) for acute ischaemic stroke (AIS) can be performed on patients

65 by way of three approaches 1) local anaesthesia (LA) at the arterial access site without

66 sedation in awake subjects, 2) administering procedural sedation, commonly referred to as

67 conscious sedation (CS) or 3) general anaesthesia (GA). Observational studies comparing GA

68 with composite non-GA cohorts of awake (LA) and sedated (CS) patients have reported

69 poorer outcomes in patients treated under $\mathrm{GA}^{1-3}$. Pooled analysis of individual patient level

70 data from the High Effective Reperfusion Using Multiple Endovascular Devices (HERMES)

71 collaboration similarly supported the avoidance of GA when feasible ${ }^{4}$. By contrast, single-

72 centre randomized trials comparing protocol based GA with CS yielded either no difference

73 or more favourable outcomes in the GA group ${ }^{5-9}$. These opposing results have been

74 acknowledged by current guidelines and the optimal anaesthetic modality for EVT remains

75 undetermined $^{10,11}$.

76

77 Performing EVT under LA without sedation obviates exposure to the sedative pharmacological agents administered in CS and GA which potentially directly disrupt cerebral haemodynamics and alter cardiorespiratory variables (such as $\mathrm{PaO} 2$ and arterial blood pressure) to the detriment of cerebral perfusion ${ }^{12}$. Another important argument to

81 perform EVT under LA is the potential delay in initiation of the EVT procedure under CS and GA due to sedation and/or intubation ${ }^{4}$. These considerations have been recognised by calls to include LA without sedation as a distinct comparator in prospective studies assessing

84 the optimal anaesthetic strategy ${ }^{13}$. To our knowledge, there are no on-going randomised controlled trials with a LA-only arm. 
87 Retrospective data differentiating subjects receiving LA without sedation from CS and GA has recently been published but individual studies have reported conflicting results for the functional outcomes between the LA, CS and GA cohorts ${ }^{14-21}$. Hence, the objective of this systematic and meta-analysis was to assess if LA without sedation resulted in superior procedural and clinical outcomes, compared to CS and GA, in AIS patients following EVT.

\section{METHODS}

\section{Search Strategy, study selection and eligibility criteria}

The study was performed according to the Preferred Reporting Items for Systematic Reviews and Meta-Analyses (PRISMA) guidelines ${ }^{22}$. We systematically searched electronic databases up to January 2021, including PubMed/MEDLINE, EMBASE, and Cochrane. The following keywords were used in combination or individually by using the Boolean operators "OR" and "AND": 'thrombectomy', 'endovascular procedures', 'stroke', 'anaesthesia', 'local anaesthesia' , 'general anaesthesia' and 'conscious sedation'. The articles were selected in 2 stages.

Firstly, the titles and abstracts were screened for relevant studies, and duplicates excluded. Secondly, the full texts were downloaded and assessed for eligibility. The reference lists of included publications were then hand-searched for additional relevant studies. This process was carried out by three assessors independently (WB, PD, AP). Any differences were resolved by consensus.

Studies evaluating one or more procedural and clinical outcomes of EVT in LA compared to CS or LA compared to GA were included. LA was defined as the use of subcutaneous anaesthetic injection only at the site of the arteriotomy, GA required the need for endotracheal intubation and CS required the need for systemic medication for sedation, without requiring advanced airway protection. Randomized and non-randomized controlled 
111 (retrospective and prospective) trials and pre- and post-intervention studies, observational and

112 cohort studies or post-hoc analyses of observational data in trials were included when a

113 control group was reported. The exclusion criteria included studies published before 2010

114 (prior to the use of modern stent retrievers/aspiration), review articles and meta-analyses,

115 guidelines, technical notes, studies in animals, studies in languages other than English,

116 studies that did not discriminate between CS and LA in the comparator arm and studies that

117 did not report our specified outcome measures. In the event of overlapping patient

118 population, only the series with the largest number of patients or the most detailed data

119 reported were included.

Data Extraction

121 Variables recorded, if available, were first line choice of anaesthetic technique (LA, CS, GA),

122 study type (retrospective, prospective), study recruitment period, sample size, mean age,

123 number of males, presence of co-morbidities (atrial fibrillation, hypertension, diabetes,

124 coronary artery disease, heart failure, hyperlipidaemia, smoking) anatomical region

125 (anterior/posterior circulation), lateralization of hemispheres (left/right), clot location (ICA,

126 M1, M2, vertebrobasilar, tandem occlusion), baseline National Institutes of Health Stroke

127 Scale (NIHSS) and modified Rankin scale (mRS), prior intravenous tissue plasminogen

128 activator (IV-tPA), Alberta stroke program early CT score (ASPECTS), anaesthesia

129 conversion, the first-line EVT technique used (aspiration, stent-retriever, combined), onset to

130 groin puncture time, groin puncture to reperfusion time, total procedure time, number of

131 passes, successful reperfusion rate and first pass effect [defined as extended or modified

132 thrombolysis in cerebral infarction (TICI) scale of $2 b$ or above], excellent functional outcome

133 defined as modified Rankin score of 1 or lower $(\mathrm{mRS} \leq 1)$ at 90 days, good functional

134 outcome defined as functional independence with a $\mathrm{mRS} \leq 2$ at 90 days, symptomatic 
intracranial haemorrhage ( $\mathrm{sICH})$ defined as any ICH with an increase of the NIHSS score of

4 or more within 24 hours or death, mortality at 90 days, and procedure related

137 complications, including vessel dissection/perforation, intra-procedural haemorrhage and new

138 or distal emboli.

\section{Outcome measures}

140 The primary outcome was good functional outcome (mRS $\leq 2)$ at 90 days. The secondary

141 clinical outcomes were excellent functional outcome (mRS $\leq 1)$, mortality and sICH. The

142 secondary procedural outcomes included successful reperfusion (TICI $\geq 2 b$ ), the first pass

143 effect, procedure related complications, door to groin puncture time, groin puncture to 144 reperfusion time.

145 Statistical analysis

146 Study characteristics and extracted variables were summarized using standard descriptive

147 statistics. Continuous variables were expressed as means and SD, and categorical variables

148 were expressed as frequencies or percentages. Meta analyses of binary outcomes were

149 expressed as odds ratio (OR) with a 95\% confidence interval (CI), and continuous variables

150 as weighted mean difference (MD) with a 95\%CI. A random effects model was used. Tests of

151 heterogeneity were conducted with the Q statistic distributed as a chi-square variate

152 (assumption of homogeneity of effect sizes). The extent of between-study heterogeneity was

153 assessed with the $\mathrm{I}^{2}$ statistic. Study heterogeneity $\mathrm{I}^{2}$ values $>50 \%$ were considered substantial

154 and $>75 \%$ deemed considerable heterogeneity. Funnel plots and Egger's test were used to

155 assess publication bias for the primary outcome. ROBINS-I ${ }^{23}$ tool was used to evaluate the

156 risk of bias of each study. P-values were two-tailed with values $<0.05$ considered statistically

157 significant. 
158 To account for the between-group heterogeneity in variables due to the inclusion of non-

159 randomized studies, we also performed analyses based on adjusted data for potential

160 confounders (adjusted OR from regression analyses or propensity matching) using the

161 generic inverse variance method. Additionally we conducted sub-group analysis for GA vs

162 non-GA and sub-group analysis for anterior circulation only. Meta-regression was not

163 specifically performed as there were fewer than ten studies included in our meta-analysis ${ }^{24}$.

164 All analyses were implemented using JASP 0.14.1.0 and Review Manager 5.4.1 software.

165 Ethics

166 This study is a systematic review and meta-analysis, and no human participant procedure was

167 involved. Informed consent and ethical approval were not essential for this study. 


\section{RESULTS}

169

170

171

172

173

174

175

176

177

178

179

180

181

182

183

184

185

186

187

188 Similarly, there was no statistical difference between LA vs CS with respect to good 189

Literature search results

We screened 921 titles and abstracts, from which 20 full-text articles were evaluated (Supplementary Figure 1). Out of those, data was extracted from 8 studies $^{14-21}$ that met the inclusion criteria. 913 studies were excluded for not reporting on LA vs GA and/or CS, not reporting the specified outcome measures, lack of full-text or duplicates.

\section{Characteristics of Included Studies}

We included 8 studies published between 2010-2020 describing 7797 patients (2797 LA, $2218 \mathrm{CS}$ and $2782 \mathrm{GA}$ ) that underwent EVT due to occlusion in the anterior circulation (7004 patients) or posterior circulation (793 patients). Six studies were prospective and 2 were retrospective cohort studies. The largest study cohort had 4429 patients (1131 LA, 1285 CA and 2013 GA), whilst the smallest study had 158 patients (111 LA and $47 \mathrm{CS}$ ). The studies are summarised in Table 1 . The detailed baseline characteristics are presented in Supplementary Figure 2.

\section{Clinical outcomes}

The type of anaesthesia (LA vs GA) was not associated with the odds of achieving good functional outcome (mRS $\leq 2$ ) at 90 days (Figure 1; 6 studies; OR=1.22, 95\%CI 0.84-1.76, $\mathrm{p}=0.3, \mathrm{I}^{2}=82 \%$ ), mortality at 90 days $\left(5\right.$ studies; $\mathrm{OR}=0.83,95 \% \mathrm{CI} 0.64-1.07, \mathrm{p}=0.15, \mathrm{I}^{2}=82 \%$, Table 2) and sICH (6 studies; OR=1.16, 95\%CI 0.88-1.58, $\mathrm{p}=0.26, \mathrm{I}^{2}=0 \%$, Table 2 ). 
190

191

192

193

194

195

196

197

198

199

200

201

202

203

204

205

206

207

208

209

210

211

212

$\mathrm{p}=0.53, \mathrm{I}^{2}=83 \%$ ), $\mathrm{sICH}\left(5\right.$ studies; OR=1.18, 95\%CI 0.85-1.64, $\mathrm{p}=0.33, \mathrm{I}^{2}=5 \%$, Table 2 ) or mortality at 90 days ( 4 studies; $\mathrm{OR}=0.88,95 \% \mathrm{CI} 0.62-1.24, \mathrm{p}=0.47, \mathrm{I}^{2}=70 \%$, Table 2 ).

However, there was a tendency towards achieving excellent functional outcome $(\mathrm{mRS} \leq 1)$ in the LA group (compared to GA) (3 studies; OR=1.44, 95\%CI 1.00-2.08, $\mathrm{p}=0.05, \mathrm{I}^{2}=70 \%$,

Table 2) but not when LA was compared to CS (3 studies; OR=1.40, 95\%CI 0.87-2.25, $\mathrm{p}=0.16, \mathrm{I}^{2}=84 \%$, Table 2 ).

\section{Procedural Outcomes}

The door to groin puncture time was statistically significantly shorter in the LA group (compared to GA) (3 studies; $\mathrm{MD}=-14.36$ mins, $95 \% \mathrm{CI}-20.91$ to $-7.81, \mathrm{p}<0.0001, \mathrm{I}^{2}=64 \%$, Table 2). However, there was no statistical difference in the groin puncture to reperfusion time ( 5 studies; $\mathrm{MD}=-1.66$ mins, $95 \% \mathrm{CI}-8.83$ to $5.50, \mathrm{p}=0.65, \mathrm{I}^{2}=83 \%$, Table 2 ), successful reperfusion $\left(\mathrm{TICI} \geq 2 \mathrm{~b}\right.$ ) (6 studies; $\mathrm{OR}=0.90,95 \% \mathrm{CI} 0.54$ to $1.49, \mathrm{p}=0.69, \mathrm{I}^{2}=88 \%$, Table 2 ), first pass effect ( 2 studies; OR=1.15, 95\%CI 0.63 to $2.12, \mathrm{p}=0.65, \mathrm{I}^{2}=76 \%$, Table 2 ), or frequency of procedure-related complications ( 4 studies; $\mathrm{OR}=1.20,95 \% \mathrm{CI} 0.55$ to 2.62 , $\mathrm{p}=0.65, \mathrm{I}^{2}=69 \%$, Table 2 ).

(1)

Similarly, there was no statistical difference between LA and CS in achieving successful reperfusion $\left(\mathrm{TICI} \geq 2 \mathrm{~b}\right.$ ) ( 5 studies; $\mathrm{OR}=0.92,95 \% \mathrm{CI} 0.56-1.50, \mathrm{p}=0.73, \mathrm{I}^{2}=86 \%$, Table 2 ) or in the frequency of procedure-related complications ( 3 studies; $\mathrm{OR}=1.17,95 \% \mathrm{CI} 0.74-1.83$, $\mathrm{p}=0.5, \mathrm{I}^{2}=0 \%$, Table 2 ). Only 1 study reported the first pass effect and door to groin puncture time for LA vs CS which precluded pooled analysis. However, the groin puncture to reperfusion time was significantly shorter in the LA group compared to CS (3 studies; MD= 7.31 mins, $95 \% \mathrm{CI}-11.44$ to $-3.19, \mathrm{p}=0.0005, \mathrm{I}^{2}=0 \%$, Table 2 ). 
214 Adjustments for unbalanced variables included at least the age, sex, baseline NIHSS score,

215 and onset to door time, whilst some studies also included the ASPECTS, co-morbidities,

216 collaterals, IV-tPA, and blood pressure (baseline systolic or mean arterial pressure). After

217 extracting data adjusted for potential confounders, there remained no statistically significant

218 difference between the anaesthesia type and good functional outcome ( $\mathrm{mRS} \leq 2)$ at 90 days

219 (GA vs LA; 5 studies; OR=0.98, 95\%CI 0.70-1.37, $\left.\mathrm{p}=0.89, \mathrm{I}^{2}=57 \%\right)$ and $(\mathrm{CS}$ vs LA; 2

220 studies; $\mathrm{OR}=0.76,95 \% \mathrm{CI} 0.17-3.45, \mathrm{p}=0.72, \mathrm{I}^{2}=96 \%$ ) (Supplementary figure 3 ). There was a

221 tendency towards increased odds of mortality for GA at 3 months (GA vs LA; 5 studies;

$222 \mathrm{OR}=1.24,95 \%$ CI 1.00-1.54, $\mathrm{p}=0.05, \mathrm{I}^{2}=0 \%$ ) but not for CS (CS vs LA; 2 studies; OR=1.16, $22395 \%$ CI $0.41-3.27, p=0.78, I^{2}=91 \%$ ) (Supplementary figure 4$)$.

225 In a subgroup analysis of GA vs non-GA (composite of CS and LA), GA was associated with 226 higher odds of mortality ( 5 studies; OR=1.18, 95\%CI 1.02-1.36, $\mathrm{p}=0.02, \mathrm{I}^{2}=8 \%$ ) but no

227 statistical difference was demonstrated for good functional outcome (mRS $\leq 2)$ at 90 days (6 228 studies; $\left.\mathrm{OR}=0.87,95 \% \mathrm{CI} 0.63-1.22, \mathrm{p}=0.42, \mathrm{I}^{2}=79 \%\right)$ and $\mathrm{sICH}(6$ studies; $\mathrm{OR}=0.90,95 \% \mathrm{CI}$ $\left.229 \quad 0.69-1.18, \mathrm{p}=0.45, \mathrm{I}^{2}=0 \%\right)$.

230 Sub-group analysis: anterior circulation

231 Analysing anterior circulation strokes, we found no statistical difference in the odds of 232 achieving 90-day good functional outcome $(\mathrm{mRS} \leq 2)$ and mortality respectively between the 233 LA vs GA groups ( 4 studies; $\mathrm{OR}=1.24,95 \% \mathrm{CI} 0.62-2.47, \mathrm{p}=0.54, \mathrm{I}^{2}=87 \%$ ) and ( 3 studies; $234 \mathrm{OR}=0.93,95 \% \mathrm{CI} 0.74-1.17, \mathrm{p}=0.55, \mathrm{I}^{2}=0 \%$ ). There were also no differences in the LA vs 
235 CS comparison ( 3 studies; OR $=1.20,95 \% \mathrm{CI} 0.53-2.70, \mathrm{p}=0.66, \mathrm{I}^{2}=91 \%$ ) and ( 2 studies; OR $236=0.98,95 \%$ CI $\left.0.51-1.90, \mathrm{p}=0.96, \mathrm{I}^{2}=85 \%\right)$.

237 Risk of bias

238 All studies had an overall moderate risk of bias (Supplementary Figure 5). Visual inspection 239 of funnel plots did not reveal asymmetry in studies that reported the primary outcome $240(\mathrm{mRs} \leq 2)$ at 90 days (Supplementary Figure 6) and there was no evidence of publication bias 241 (Egger's test; LA vs GA, $\mathrm{p}=0.99$ and LA vs CS, $\mathrm{p}=0.56$ ). 


\section{DISCUSSION}

243 In this systematic review and meta-analysis the use of LA without sedation for EVT in AIS

244 was shown to yield similar rates of good functional outcome (mRS $\leq 2$ at 90 days) compared

245 to CS and GA. No statistical differences were found in mortality, successful re-canalisation

246 (TICI $\geq 2 \mathrm{~b}$ ), sICH, procedural times or complications in the unadjusted analysis. There was a

247 tendency towards achieving excellent functional outcome $(\mathrm{mRS} \leq 1)$ in the LA group versus

248 GA comparison. There was also a tendency towards higher odds of 90-day mortality in GA

249 versus LA using extracted data adjusted for confounders.

250

251 The findings in our study are difficult to directly compare with recent meta-analyses that

252

253

254

255

256

257

258

259

260

261

262

263

264

265

266 assessed GA versus a merged non-GA (LA and CS) group and did not include any of the studies in the present analysis. Gravel et $\mathrm{al}^{2}$ found non-GA to be associated with better 90 day functional outcomes and mortality in their unadjusted analysis. Interestingly, Goyal et $\mathrm{al}^{3}$ reported no difference between anaesthesia type (GA vs non-GA) for 90-day good functional outcomes when excluding studies published before the stent-retriever era. Furthermore, the difference in their unadjusted analysis did not retain significance when imbalances in baseline NIHSS scores were factored by way of meta-regression. The studies in our analysis also predominantly included patients who received modern stent retriever/aspiration treatment and it is plausible that any potential 'real world' effect-size of anaesthetic choice has attenuated with increasing levels of experience of anaesthesiologists in the setting of EVT for AIS.

One of the rationales for using LA without sedation is to avoid iatrogenic hypotension from intravenous or inhaled sedative agents. Samuels et $\mathrm{al}^{25}$ recently reported patients treated under CS had a lower average procedural BP and more BP drops compared to patients treated under LA. Whilst there is evidence that blood pressure (BP) drops are associated with poor 
267 functional outcome due to collateral failure 26,27 ; the neurotoxic or neuroprotective effects of

268 hypnotic agents and optimal intra- and peri-procedural BP targets during the acute ischaemia-

269 reperfusion injury are incompletely understood ${ }^{28}$. Of note, in the present analysis, only one

270 of the included studies reported intra-procedural BP measurements and found no statistical

271 differences in their selected haemodynamic parameters ${ }^{18}$.

272

273 The purported disadvantages of using LA alone are lack of airway protection, patient

274 movement and patient discomfort. These factors may require conversion to either CS or GA

275 with resultant delays in procedural times and a theoretical detrimental effect on outcomes.

276 Our analysis showed a conversion rate of LA to GA (17.5\%), comparable to those reported

277 for CS to GA in the previous randomized trials (15.6\% in the anesthesia during stroke

278 (ANSTROKE) trial $^{6}$ and $14.2 \%$ in the sedation versus intubation for endovascular stroke

279 treatment (SIESTA) trial ${ }^{5}$. Conversion rates from CS to GA $(8.8 \%)$ were however lower in

280 our analysis. Despite this, Flottmann et a ${ }^{19}$ found similar rates of functional independence

281 when the $9.8 \%$ of patients in their cohort that required emergency conversion were compared

282 to the primary anaesthesia groups. On the other hand, LA allows for real-time monitoring of

283 the patient's neurological status which may guide intra-procedural treatment decisions. Cost

284 and length of stay in hospital or intensive care were not assessed as outcome variables but

285 these are also potential resource factors favouring a LA first strategy ${ }^{29}$. Radiation exposure

286 was also not assessed however a recent study reported no difference between GA and CS

287 comparisons $^{30}$.

289 Unsurprisingly, due to the logistics of anaesthetic induction and intubation, we found significantly shorter door-to-groin puncture times in the LA group compared to the GA

291 group, which was also shown to favour LA versus CS in the single study reporting on this 
metric $^{18}$. No statistical difference was identified in groin puncture-to-reperfusion times in the LA vs GA comparison ( \pm SD, minutes) $52.5 \pm 31.8$ and $56.0 \pm 34.5$ respectively. This is in contrast to the previous meta-analysis by Goyal et $\mathrm{al}^{3}$ that found statistically significant longer groin puncture to reperfusion times in the non-GA cohort compared to GA $(81.3 \pm 32.3$ and $75.7 \pm 25.8$ respectively). This may be explained by the overall marked reduction in the procedural times between the studies which in turn may reflect continued improvement of modern-day EVT techniques and increasing levels of operator experience. In addition to these factors, refinement in selection of patients likely to remain compliant during EVT performed under LA without sedation may also explain why no differences were revealed in successful reperfusion ( $\mathrm{TICI} \geq 2 \mathrm{~b}$ ) or procedural complications.

Our analysis included several limitations. Firstly, due to the observational design of all included studies, confounding by indication may have influenced the results. Patient related factors could have influenced the decision whether or not to perform EVT under LA,CS or GA. Secondly, there were differences in between-group baseline characteristics, including baseline NIHSS. Whilst these differences were small, we also performed a meta-analysis of extracted adjusted data which revealed similar outcomes. Thirdly, four of the included studies $^{14,16,18,19}$ provided data on a per-protocol analysis basis, whilst the rest provided data on the basis of an intention-to-treat analysis, which may have confounded the final outcomes.

311 Fourthly, a disproportionate number of posterior circulation strokes were included in the GA group which tend to have worse clinical outcomes. However, no statistically significant difference remained following sub-group analysis for anterior circulation stroke only.

\section{Conclusion:}

316 To our knowledge, this is the first meta-analysis assessing LA as a distinct comparator versus 
317 CS and GA for EVT in AIS. LA without sedation was not significantly superior to CS or GA

318 in improving functional outcome or mortality. However, as the majority of the data is drawn

319 from registries, the quality of included studies impairs interpretation; the inclusion of a LA

320 only arm in future multi-centre randomised trials remains a gold-standard for assessing an

321 effect size between anaesthetic modalities. Nonetheless, these findings reflect 'real world'

322 practice and conducting a well-designed sufficiently powered trial with generalisability may

323 prove challenging. In the interim, we advise a patient-tailored and expertise-dependent

324 approach to optimal anaesthetic management.

325

326

327

328 


\section{REFERENCES}

1. Brinjikji W, Pasternak J, Murad MH, et al. Anesthesia-related outcomes for endovascular stroke revascularization: A systematic review and meta-analysis. Stroke. 2017. doi:10.1161/STROKEAHA.117.017786

2. Gravel G, Boulouis G, Benhassen W, et al. Anaesthetic management during intracranial mechanical thrombectomy: Systematic review and meta-analysis of current data. J Neurol Neurosurg Psychiatry. 2019. doi:10.1136/jnnp-2018-318549

3. Goyal N, Malhotra K, Ishfaq MF, et al. Current evidence for anesthesia management during endovascular stroke therapy: Updated systematic review and meta-analysis. $J$ Neurointerv Surg. 2019. doi:10.1136/neurintsurg-2018-013916

4. Campbell BCV, van Zwam WH, Goyal M, et al. Effect of general anaesthesia on functional outcome in patients with anterior circulation ischaemic stroke having endovascular thrombectomy versus standard care: a meta-analysis of individual patient data. Lancet Neurol. 2018. doi:10.1016/S1474-4422(17)30407-6

5. Schönenberger S, Uhlmann L, Hacke W, et al. Effect of conscious sedation vs general anesthesia on early neurological improvement among patients with ischemic stroke undergoing endovascular thrombectomy: A randomized clinical trial. JAMA - J Am Med Assoc. 2016. doi:10.1001/jama.2016.16623

6. Hendén PL, Rentzos A, Karlsson JE, et al. General Anesthesia Versus Conscious Sedation for Endovascular Treatment of Acute Ischemic Stroke: The AnStroke Trial (Anesthesia during Stroke). Stroke. 2017. doi:10.1161/STROKEAHA.117.016554

7. Simonsen CZ, Yoo AJ, Sørensen LH, et al. Effect of general anesthesia and conscious sedation during endovascular therapy on infarct growth and clinical outcomes in acute ischemic stroke a randomized clinical trial. JAMA Neurol. 2018. doi:10.1001/jamaneurol.2017.4474 
355 8. Schönenberger S, Hendén PL, Simonsen CZ, et al. Association of General Anesthesia vs Procedural Sedation with Functional Outcome among Patients with Acute Ischemic Stroke Undergoing Thrombectomy: A Systematic Review and Meta-analysis. JAMA J Am Med Assoc. 2019. doi:10.1001/jama.2019.11455

9. Sørensen LH, Speiser L, Karabegovic S, et al. Safety and quality of endovascular therapy under general anesthesia and conscious sedation are comparable: Results from the GOLIATH trial. J Neurointerv Surg. 2019. doi:10.1136/neurintsurg-2019-014712

10. Turc G, Bhogal P, Fischer U, et al. European Stroke Organisation (ESO) - European Society for Minimally Invasive Neurological Therapy (ESMINT) Guidelines on Mechanical Thrombectomy in Acute Ischemic Stroke. J Neurointerv Surg. 2019. doi:10.1136/neurintsurg-2018-014569

11. Powers WJ, Rabinstein AA, Ackerson T, et al. 2018 Guidelines for the Early Management of Patients With Acute Ischemic Stroke: A Guideline for Healthcare Professionals From the American Heart Association/American Stroke Association. Stroke. 2018. doi:10.1161/STR.0000000000000158

12. Venema AM, Uyttenboogaart M, Absalom AR. Land of confusion: anaesthetic management during thrombectomy for acute ischaemic stroke. Br J Anaesth. 2019.

13. Rabinstein AA, Kallmes DF. Optimal anesthetic strategy for endovascular stroke therapy Begging for a good trial. Neurology. 2018. doi:10.1212/WNL.0000000000005754

14. Cappellari M, Pracucci G, Forlivesi S, et al. General Anesthesia Versus Conscious Sedation and Local Anesthesia during Thrombectomy for Acute Ischemic Stroke.

379 15. Benvegnù F, Richard S, Marnat G, et al. Local Anesthesia without Sedation during 
Thrombectomy for Anterior Circulation Stroke Is Associated with Worse Outcome. Stroke. 2020. doi:10.1161/STROKEAHA.120.029194

382

16. Goldhoorn RJB, Bernsen MLE, Hofmeijer J, et al. Anesthetic management during endovascular treatment of acute ischemic stroke in the MR CLEAN Registry. Neurology. 2020. doi:10.1212/WNL.0000000000008674

17. Pop R, Severac F, Happi Ngankou E, et al. Local anesthesia versus general anesthesia during endovascular therapy for acute stroke: a propensity score analysis. $J$ Neurointerv Surg. 2020. doi:10.1136/neurintsurg-2020-015916

18. Marion JT, Seyedsaadat SM, Pasternak JJ, Rabinstein AA, Kallmes DF, Brinjikji W. Association of local anesthesia versus conscious sedation with functional outcome of acute ischemic stroke patients undergoing embolectomy. Interv Neuroradiol. 2020. doi:10.1177/1591019920923831

392

19. Flottmann F, Leischner H, Broocks G, et al. Emergency conversion to general anesthesia is a tolerable risk in patients undergoing mechanical thrombectomy. Am J Neuroradiol. 2020. doi:10.3174/ajnr.A6321

20. Wu L, Jadhav AP, Zhao W, et al. General anesthesia vs local anesthesia during mechanical thrombectomy in acute ischemic stroke. J Neurol Sci. 2019. doi:10.1016/j.jns.2019.05.034

21. Wu L, Jadhav AP, Chen J, et al. Local anesthesia vs general anesthesia during endovascular therapy for acute posterior circulation stroke. J Neurol Sci. 2020;416:117045. doi:10.1016/j.jns.2020.117045

22. Moher D, Shamseer L, Clarke M, et al. Preferred reporting items for systematic review 402 and meta-analysis protocols (PRISMA-P) 2015 statement. Rev Esp Nutr Humana y Diet. 2016. doi:10.1186/2046-4053-4-1

23. Sterne JAC, Hernán MA, Reeves BC, et al. ROBINS-I: a tool for assessing risk of bias 
in non-randomised studies of interventions. BMJ. 2016;355.

406

407

408

409

410

411

412

413

414

415

416

417

418

419

420

421

422

423

424

425

426

427

428

429

430

24. Higgins JPT, Thomas J, Chandler J, Cumpston M, Li T, Page MJ WV. Cochrane Handbook for Systematic Reviews of Interventions version 6.0 (updated July 2019). Cochrane, 2019. Handbook. 2019.

25. Samuels N, van de Graaf RA, van den Berg CAL, et al. Blood Pressure During Endovascular Treatment Under Conscious Sedation or Local Anesthesia. Neurology. 2021. doi:10.1212/WNL.0000000000011006

26. Petersen NH, Ortega-Gutierrez S, Wang A, et al. Decreases in Blood Pressure during Thrombectomy Are Associated with Larger Infarct Volumes and Worse Functional Outcome. Stroke. 2019. doi:10.1161/STROKEAHA.118.024286

27. Valent A, Sajadhoussen A, Maier B, et al. A 10\% blood pressure drop from baseline during mechanical thrombectomy for stroke is strongly associated with worse neurological outcomes. J Neurointerv Surg. 2020. doi:10.1136/neurintsurg-2019015247

28. Maïer B, Fahed R, Khoury N, et al. Association of blood pressure during thrombectomy for acute ischemic stroke with functional outcome a systematic review. Stroke. 2019. doi:10.1161/STROKEAHA.119.024915

29. Julie H, Dereux C, Lukaszewicz AC. Anaesthetic strategy during endovascular therapy. Anaesth Crit Care Pain Med. 2019. doi:10.1016/j.accpm.2018.07.007

30. Hemmerich F, Weyland CS, Schönenberger S, et al. Effect of mode of anesthesia on radiation exposure in patients undergoing endovascular recanalization of anterior circulation embolic stroke. J Neurointerv Surg. 2020. doi:10.1136/neurintsurg-2019015357 


\begin{tabular}{|c|c|c|c|c|c|c|}
\hline $\begin{array}{l}\text { Author, Year of } \\
\text { Study }\end{array}$ & Country & $\begin{array}{l}\text { Study } \\
\text { recruitment } \\
\text { period }\end{array}$ & Study Design & Comparator & Sample size, $n$ & Risk of bias \\
\hline Benvegnu, $2020^{15}$ & France & 2018 & $\begin{array}{l}\text { Prospective multi centre } \\
\text { ETIS registry }\end{array}$ & LA vs CS & $\begin{array}{l}\mathrm{LA}=272 \\
\mathrm{CS}=636\end{array}$ & $\mathrm{M}$ \\
\hline Cappellari, $2020^{14}$ & Italy & 2011 to 2017 & $\begin{array}{l}\text { Prospective multi centre } \\
\text { IRETAS registry }\end{array}$ & LA vs CS vs GA & $\begin{array}{l}\mathrm{LA}=1131 \\
\mathrm{CS}=1285 \\
\mathrm{GA}=2013\end{array}$ & $\mathrm{M}$ \\
\hline Flottmann, $2020^{19}$ & Germany & 2015 to 2018 & Retrospective single centre & LA vs CS vs GA & $\begin{array}{l}\mathrm{LA}=794 \\
\mathrm{CS}=76 \\
\mathrm{GA}=59\end{array}$ & $\mathrm{M}$ \\
\hline Goldhoorn, $2020^{16}$ & Netherlands & 2014 to 2016 & $\begin{array}{l}\text { Prospective multi centre } \\
\text { MR CLEAN registry }\end{array}$ & LA vs CS vs GA & $\begin{array}{l}\mathrm{LA}=821 \\
\mathrm{CS}=174 \\
\mathrm{GA}=381\end{array}$ & $\mathrm{M}$ \\
\hline Marion, $2020^{18}$ & USA & 2014 to 2018 & Single centre retrospective & LA vs CS & $\begin{array}{l}\mathrm{LA}=111 \\
\mathrm{CS}=47\end{array}$ & M \\
\hline Pop, $2020^{17}$ & France & 2018 to 2018 & $\begin{array}{l}\text { Prospective multi centre } \\
\text { observational registry }\end{array}$ & LA vs GA & $\begin{array}{l}\mathrm{LA}=219 \\
\mathrm{GA}=142\end{array}$ & M \\
\hline $\mathrm{Wu}, 2019^{20}$ & China & 2013 to 2017 & $\begin{array}{l}\text { Prospective single centre } \\
\text { observational registry }\end{array}$ & LA vs GA & $\begin{array}{l}\mathrm{LA}=112 \\
\mathrm{GA}=75\end{array}$ & $\mathrm{M}$ \\
\hline $\mathrm{Wu}, 2020^{21}$ & China & 2012 to 2018 & $\begin{array}{l}\text { Prospective single centre } \\
\text { observational registry }\end{array}$ & LA vs GA & $\begin{array}{l}\mathrm{LA}=71 \\
\mathrm{GA}=112\end{array}$ & $\mathrm{M}$ \\
\hline
\end{tabular}

Table 1: Characteristics of included studies 


\begin{tabular}{|c|c|c|c|c|c|c|c|c|c|c|c|c|c|c|c|c|c|c|c|}
\hline & \multirow{2}{*}{$\begin{array}{c}\text { GA } \\
\mathrm{n} / \mathrm{N} \\
(\%) \text { or } \\
\text { mean } \pm \\
\mathrm{SD} / \mathrm{N} \\
\end{array}$} & \multirow{2}{*}{$\begin{array}{c}\text { CS } \\
\mathrm{n} / \mathrm{N} \\
(\%) \text { or } \\
\text { mean } \pm \\
\mathrm{SD} / \mathrm{N} \\
\end{array}$} & \multirow{2}{*}{$\begin{array}{c}\mathbf{G A}+\mathbf{C} \\
\mathbf{S} \\
\mathrm{n} / \mathrm{N} \\
(\%) \text { or } \\
\text { mean } \pm \\
\mathrm{SD} / \mathrm{N} \\
\end{array}$} & \multirow{2}{*}{$\begin{array}{c}\text { LA } \\
\mathrm{n} / \mathrm{N} \\
(\%) \text { or } \\
\text { mean } \pm \\
\mathrm{SD} / \mathrm{N} \\
\end{array}$} & \multicolumn{5}{|c|}{ LA vs GA } & \multicolumn{5}{|c|}{ LA vs CS } & \multicolumn{5}{|c|}{ LA vs $(\mathbf{G A}+\mathbf{C S})$} \\
\hline & & & & & $\begin{array}{l}\text { numbe } \\
\mathrm{r} \text { of } \\
\text { studies }\end{array}$ & $\begin{array}{l}\text { OR, or } \\
\text { MD }\end{array}$ & $\begin{array}{l}95 \% \\
\mathrm{CI}\end{array}$ & $\begin{array}{c}\mathrm{P}- \\
\text { value }\end{array}$ & $I^{2}(\%)$ & $\begin{array}{c}\text { numbe } \\
\mathrm{r} \text { of } \\
\text { studies }\end{array}$ & $\begin{array}{l}\text { OR, or } \\
\text { MD }\end{array}$ & $\begin{array}{l}95 \% \\
\mathrm{CI}\end{array}$ & $\begin{array}{c}\mathrm{P}- \\
\text { value }\end{array}$ & $\mathrm{I}^{2}(\%)$ & $\begin{array}{c}\text { numbe } \\
\mathrm{r} \text { of } \\
\text { studies }\end{array}$ & $\begin{array}{l}\mathrm{OR} \\
\mathrm{MD}\end{array}$ & $\begin{array}{c}95 \% \\
\mathrm{CI}\end{array}$ & $\begin{array}{c}\mathrm{P}- \\
\text { value }\end{array}$ & $\mathrm{I}^{2}(\%)$ \\
\hline \multicolumn{20}{|c|}{ Clinical outcomes } \\
\hline $\begin{array}{l}(\mathrm{mRS} \leq 2) \text { at } 90 \\
\text { days }\end{array}$ & $\begin{array}{c}1077 / 2 \\
651 \\
(40.6) \\
\end{array}$ & $\begin{array}{c}929 / 20 \\
74 \\
(44.8) \\
\end{array}$ & $\begin{array}{c}2006 / 4 \\
725 \\
(42.5) \\
\end{array}$ & $\begin{array}{c}1217 / 2 \\
733 \\
(44.5) \\
\end{array}$ & 6 & 1.22 & $\begin{array}{r}0.84- \\
1.76 \\
\end{array}$ & 0.30 & 82 & 8 & 1.01 & $\begin{array}{c}0.73- \\
1.39 \\
\end{array}$ & 0.98 & 80 & 8 & 1.05 & $\begin{array}{c}0.77- \\
1.42 \\
\end{array}$ & 0.77 & 83 \\
\hline $\begin{array}{l}(\mathrm{mRS} \leq 1) \text { at } 90 \\
\text { days }\end{array}$ & $\begin{array}{c}682 / 23 \\
45 \\
(29.1)\end{array}$ & $\begin{array}{c}614 / 19 \\
58 \\
(31.4)\end{array}$ & $\begin{array}{c}1296 / 4 \\
304 \\
(30.1)\end{array}$ & $\begin{array}{l}697 / 22 \\
52(31)\end{array}$ & 3 & 1.44 & $\begin{array}{l}1.00- \\
2.08\end{array}$ & $0.05 *$ & 70 & 3 & 1.40 & $\begin{array}{l}0.87- \\
2.25 \\
\end{array}$ & 0.16 & 84 & 4 & 1.31 & $\begin{array}{c}0.91- \\
1.90\end{array}$ & 0.15 & 82 \\
\hline sICH & $\begin{array}{l}86 / 242 \\
8(3.5)\end{array}$ & $\begin{array}{l}84 / 203 \\
3(4.1)\end{array}$ & $\begin{array}{c}170 / 44 \\
61 \\
(3.8)\end{array}$ & $\begin{array}{c}146 / 27 \\
40 \\
(5.3)\end{array}$ & 6 & 1.18 & $\begin{array}{l}0.88- \\
1.58\end{array}$ & 0.26 & 0 & 5 & 1.18 & $\begin{array}{l}0.85- \\
1.64\end{array}$ & 0.33 & 5 & 8 & 1.17 & $\begin{array}{l}0.92- \\
1.48\end{array}$ & 0.20 & 0 \\
\hline Death & $\begin{array}{c}588 / 25 \\
97 \\
(22.6) \\
\end{array}$ & $\begin{array}{c}411 / 20 \\
05 \\
(20.5) \\
\end{array}$ & $\begin{array}{c}999 / 46 \\
02 \\
(21.7) \\
\end{array}$ & $\begin{array}{c}536 / 26 \\
47 \\
(20.2) \\
\end{array}$ & 5 & 0.83 & $\begin{array}{c}0.64- \\
1.07 \\
\end{array}$ & 0.15 & 51 & 4 & 0.88 & $\begin{array}{c}0.62- \\
1.24 \\
\end{array}$ & 0.47 & 70 & 6 & 0.92 & $\begin{array}{l}0.72- \\
1.18 \\
\end{array}$ & 0.50 & 61 \\
\hline \multicolumn{20}{|c|}{ Procedural outcomes } \\
\hline $\begin{array}{l}\text { Successful } \\
\text { reperfusion } \\
\text { (TICI } \geq 2 b) \\
\end{array}$ & $\begin{array}{c}2063 / 2 \\
764 \\
(74.6) \\
\end{array}$ & $\begin{array}{c}1615 / 2 \\
151 \\
(75.1) \\
\end{array}$ & $\begin{array}{c}3678 / 4 \\
915 \\
(74.8) \\
\end{array}$ & $\begin{array}{c}1963 / 2 \\
788 \\
(70.4) \\
\end{array}$ & 6 & 0.90 & $\begin{array}{l}0.54- \\
1.49\end{array}$ & 0.69 & 88 & 5 & 0.92 & $\begin{array}{l}0.56- \\
1.50\end{array}$ & 0.73 & 86 & 8 & 0.76 & $\begin{array}{c}0.50- \\
1.15\end{array}$ & 0.20 & 87 \\
\hline $\begin{array}{l}\text { First pass } \\
\text { effect }\end{array}$ & $\begin{array}{c}621 / 12 \\
58 \\
(49.4) \\
\end{array}$ & $\begin{array}{c}481 / 90 \\
5 \\
(53.1) \\
\end{array}$ & $\begin{array}{c}1102 / 2 \\
163 \\
(50.9) \\
\end{array}$ & $\begin{array}{c}564 / 97 \\
7 \\
(57.7) \\
\end{array}$ & 2 & 1.15 & $\begin{array}{l}0.63- \\
2.12 \\
\end{array}$ & 0.65 & 76 & 1 & NA & NA & NA & NA & 2 & 1.12 & $\begin{array}{c}0.66- \\
1.91 \\
\end{array}$ & 0.67 & 70 \\
\hline $\begin{array}{l}\text { Procedure } \\
\text { related } \\
\text { complications } \\
\end{array}$ & $\begin{array}{c}57 / 388 \\
(14.7) \\
\end{array}$ & $\begin{array}{c}54 / 669 \\
(8.1) \\
\end{array}$ & $\begin{array}{c}111 / 10 \\
57 \\
(10.5) \\
\end{array}$ & $\begin{array}{c}109 / 84 \\
4 \\
(12.9) \\
\end{array}$ & 4 & 1.20 & $\begin{array}{l}0.55- \\
2.62 \\
\end{array}$ & 0.65 & 69 & 3 & 1.17 & $\begin{array}{l}0.74- \\
1.83\end{array}$ & 0.50 & 0 & 6 & 1.18 & $\begin{array}{c}0.76- \\
1.81 \\
\end{array}$ & 0.46 & 39 \\
\hline $\begin{array}{l}\text { Door to groin } \\
\text { puncture time } \\
\text { (mins) }\end{array}$ & $\begin{array}{c}70.8 \pm 3 \\
7.1 / 32 \\
9\end{array}$ & $\begin{array}{l}81.3 \pm 4 \\
9.7 / 47\end{array}$ & $\begin{array}{c}72.2 \pm 3 \\
9 / 376\end{array}$ & $\begin{array}{c}53.4 \pm 3 \\
6.8 / 51 \\
3\end{array}$ & 3 & -14.36 & $\begin{array}{c}-20.91 \\
\text { to }- \\
7.81\end{array}$ & $\begin{array}{l}<0.001 \\
*\end{array}$ & 64 & 1 & NA & NA & NA & NA & 4 & -15.06 & $\begin{array}{c}-20.35 \\
\text { to }- \\
9.77\end{array}$ & $\begin{array}{c}<0.001 \\
*\end{array}$ & 46 \\
\hline $\begin{array}{l}\text { Groin } \\
\text { puncture to } \\
\text { reperfusion } \\
\text { time (mins) } \\
\end{array}$ & $\begin{array}{c}56 \pm 34 \\
5 / 769\end{array}$ & $\begin{array}{c}54.8 \pm 3 \\
3.5 / 29 \\
7 \\
\end{array}$ & $\begin{array}{c}55.6 \pm 3 \\
4.2 / 10 \\
66 \\
\end{array}$ & $\begin{array}{c}52.5 \pm 3 \\
1.8 / 14 \\
28 \\
\end{array}$ & 5 & -1.66 & $\begin{array}{l}-8.83 \\
\text { to } 5.50\end{array}$ & 0.65 & 83 & 3 & -7.31 & $\begin{array}{c}-11.44 \\
\text { to }- \\
3.19 \\
\end{array}$ & $\begin{array}{l}<0.001 \\
*\end{array}$ & 0 & 6 & -2.23 & $\begin{array}{l}-7.28 \\
\text { to } 2.61\end{array}$ & 0.36 & 70 \\
\hline $\begin{array}{l}\text { Onset to groin } \\
\text { puncture } \\
\text { (mins) }\end{array}$ & $\begin{array}{c}255.4 \pm \\
128.9 / \\
2451 \\
\end{array}$ & $\begin{array}{c}234.4 \pm \\
91.9 / 2 \\
006\end{array}$ & $\begin{array}{c}245.9 \pm \\
114.2 / \\
4457 \\
\end{array}$ & $\begin{array}{c}222.9 \pm \\
157.5 / \\
2285 \\
\end{array}$ & 4 & -24.03 & $\begin{array}{c}-66.50 \\
\text { to } \\
18.44 \\
\end{array}$ & 0.27 & 95 & 3 & -13.62 & $\begin{array}{l}-52.39 \\
\text { to } \\
25.15\end{array}$ & 0.49 & 96 & 4 & -15.18 & $\begin{array}{c}-47.41 \\
\text { to } \\
17.05 \\
\end{array}$ & 0.36 & 95 \\
\hline
\end{tabular}

$\mathrm{LA}=$ local anaesthesia, $\mathrm{CS}=$ conscious sedation, $\mathrm{GA}=$ general anaesthesia, $\mathrm{n}=$ number of events, $\mathrm{N}=$ number of patients, $\mathrm{SD}=$ standard deviation, $\mathrm{OR}=$ odds ratio, $\mathrm{CI}=$ confidence interval, $\mathrm{MD}=$ mean difference, $\mathrm{mRS}=$ modified Rankin scale, $\mathrm{sICH}=$ symptomatic intracranial haemorrhage, $\mathrm{TICI}=$ thrombolysis in cerebral infarction, NA= not available. $*=$ statistically significant

Table 2: Meta-analysis of outcomes according to anaesthesia types. 
449 Figure 1: Forest plot demonstrating the odds of a good functional outcome $(\mathrm{mRS} \leq 2)$ at 90

451

452

453

LA vs GA

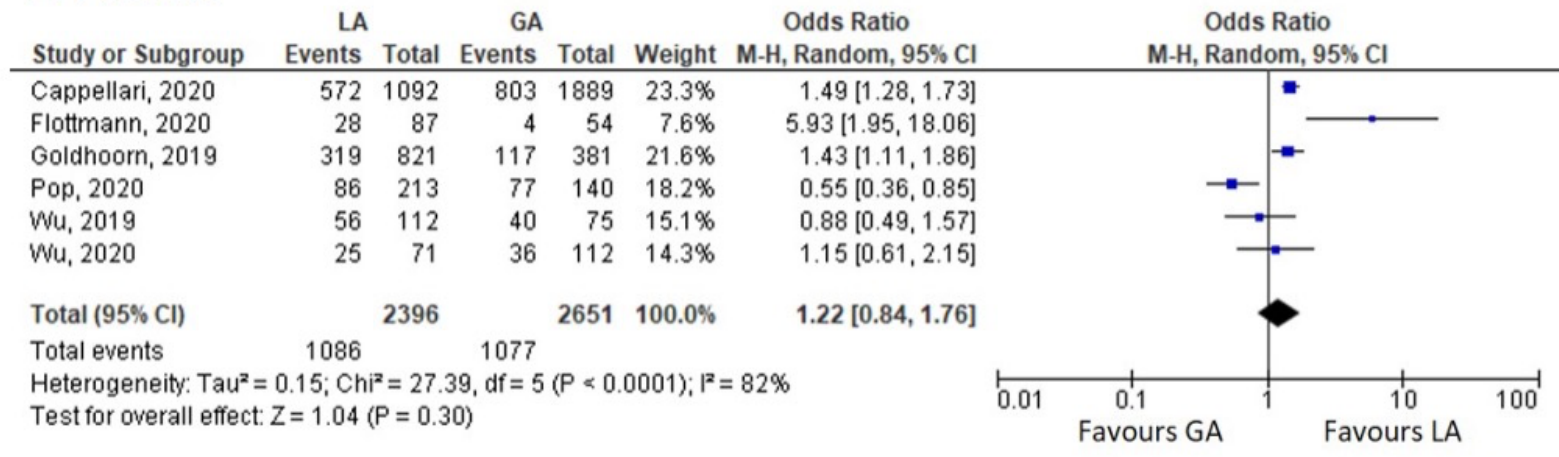

454

455

456

457 Figure 2: Forest plot demonstrating the odds of a good functional outcome (mRS $\leq 2)$ at 90

458 days comparing local anaesthesia (LA) and conscious sedation (CS).

459

460

\section{LA vs CS}

LA CS

Study or Subgroup Events Total Events Total Weight M-H, Random, 95\% C

Benevegnu, 2020

Cappellari, 2020

Flottmann, 2020

Goldhoorn, 2019

Marion, 2019

Total $(95 \% \mathrm{Cl})$

Total events

Heterogeneity: $\mathrm{Tau}^{2}=0.16 ; \mathrm{Chi}^{2}=23.81, \mathrm{df}=4(\mathrm{P} \propto 0.0001) ; \mathrm{I}^{2}=83 \%$

Test for overall effect: $Z=0.62(P=0.53)$

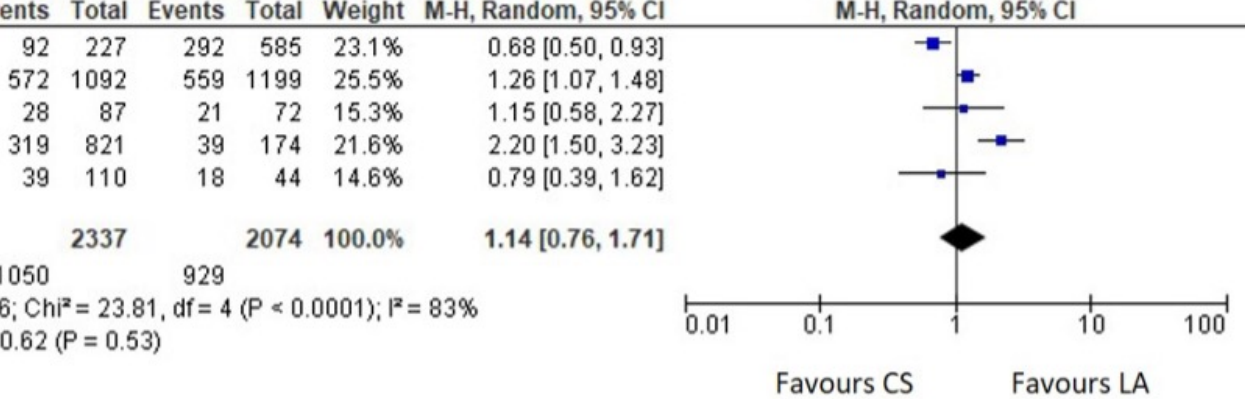



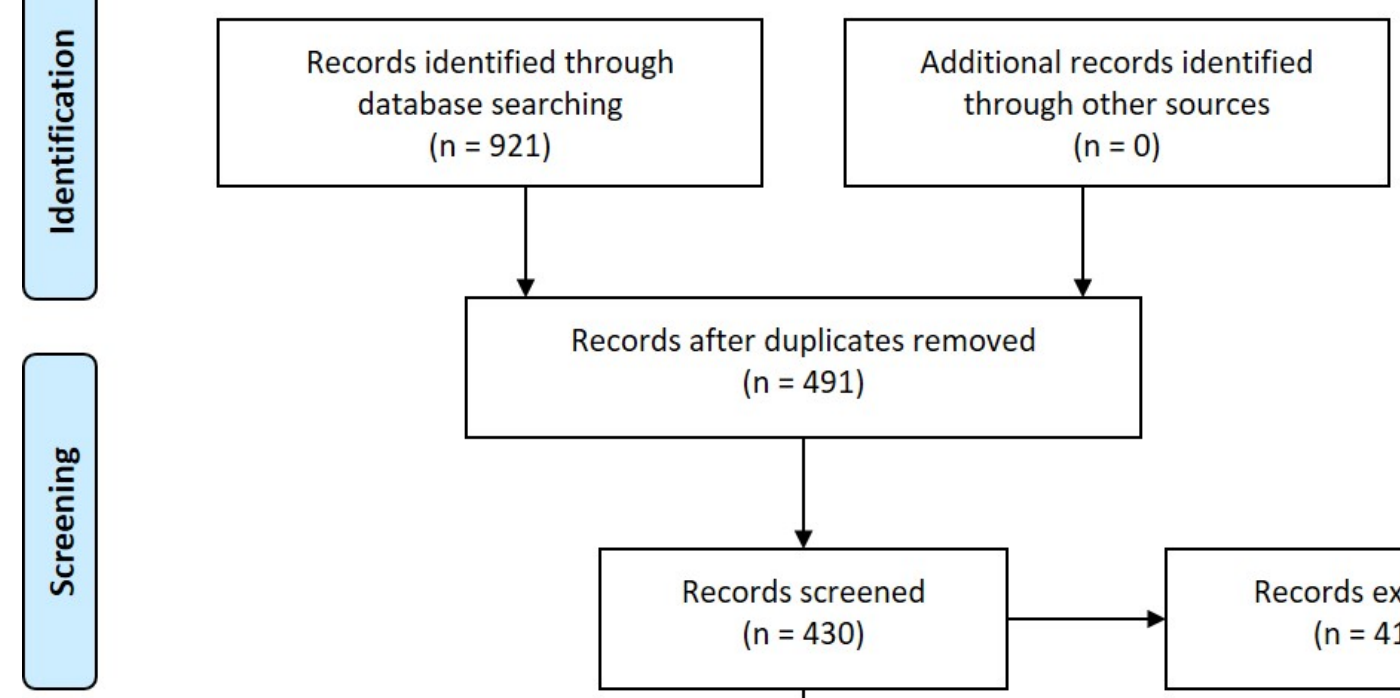

Records after duplicates removed

$$
\text { ( } n=491)
$$

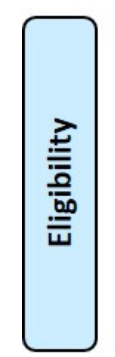

Studies included in qualitative synthesis
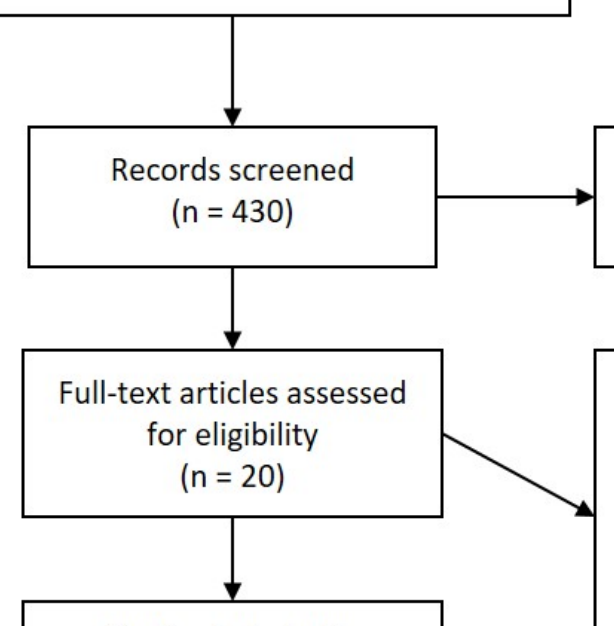

Records excluded $(n=410)$

Studies included in quantitative synthesis (meta-analysis)

$$
(n=8)
$$

Full-text articles excluded, with reasons

-Overlapping population -Not differentiating LA and CS cohorts $(n=12)$

468 Supplementary Figure 1: PRISMA Flow chart of study selection.

469

470

471

472 


\begin{tabular}{|c|c|c|c|c|}
\hline Feature & $\begin{array}{c}\text { GA, } \mathbf{n} / \mathbf{N}(\%) \text { or } \\
\text { mean } \pm \mathbf{S D} / \mathbf{N}\end{array}$ & $\begin{array}{c}\mathrm{CS}, \mathbf{n} / \mathrm{N}(\%) \text { or } \\
\text { mean } \pm \mathrm{SD} / \mathrm{N}\end{array}$ & $\begin{array}{c}\mathrm{GA}+\mathrm{CS}, \mathbf{n} / \mathbf{N}(\%) \text { or } \\
\text { mean } \pm \mathrm{SD} / \mathbf{N}\end{array}$ & $\begin{array}{c}\mathrm{LA}, \mathbf{n} / \mathbf{N}(\%) \text { or } \\
\text { mean } \pm \mathrm{SD} / \mathbf{N}\end{array}$ \\
\hline \multicolumn{5}{|c|}{ Socio-demographics } \\
\hline Sample size & 2782 & 2218 & 5000 & 2797 \\
\hline Gender (Male) & $1549 / 2782(55.7)$ & $1063 / 2217(47.9)$ & $2611 / 4999(52.2)$ & $1420 / 2796(50.8)$ \\
\hline Age (years) & $69.2 \pm 15.1 / 2782$ & $71.7 \pm 14.2 / 2218$ & $70.3 \pm 14.8 / 5000$ & $70.9 \pm 14.0 / 2797$ \\
\hline \multicolumn{5}{|c|}{ Baseline characteristics } \\
\hline Baseline NIHSS & $18.0 \pm 6.6 / 2601$ & $16.6 \pm 6.1 / 2186$ & $17.4 \pm 6.4 / 4787$ & $15.9 \pm 6.7 / 2792$ \\
\hline Baseline mRS $(\leq 1)$ & $1710 / 2157(79.3)$ & $1168 / 1360(85.9)$ & $2878 / 3517(81.8)$ & $1668 / 2134(78.2)$ \\
\hline ASPECTS & $9.0 \pm 1.8 / 1757$ & $8.7 \pm 1.8 / 1855$ & $8.8 \pm 1.8 / 3612$ & $8.8 \pm 1.6 / 1827$ \\
\hline Good collaterals & $623 / 1259(49.5)$ & $366 / 694(52.7)$ & 989/1953 (50.6) & 496/1255 (39.5) \\
\hline IV-thrombolysis & $1380 / 2778(49.7)$ & $1203 / 2212(54.4)$ & $2583 / 4990(51.8)$ & $1680 / 2795(60.1)$ \\
\hline Anaesthesia conversion & $\mathrm{N} / \mathrm{A}$ & $58 / 661(8.8)$ & N/A & $97 / 553(17.5)$ \\
\hline \multicolumn{5}{|c|}{ Co-morbidities } \\
\hline HTN & $1526 / 2420(63.1)$ & 1265/198 (63.6) & $2791 / 4409(63.3)$ & $1642 / 2707(60.7)$ \\
\hline $\mathrm{DM}$ & $451 / 2420(18.6)$ & 363/1986 (18.3) & $814 / 4406(18.5)$ & 485/2707 (17.9) \\
\hline Hyperlipidaemia & $693 / 2420(28.6)$ & $552 / 1983(27.8)$ & $1245 / 4403(28.3)$ & $776 / 2707$ (28.7) \\
\hline $\mathrm{AF}$ & $581 / 2278(25.5)$ & 443/1366 (32.4) & $1023 / 3644(28.1)$ & $690 / 2251(30.7)$ \\
\hline Prior Stroke & $175 / 2107(8.3)$ & $85 / 1290(6.6)$ & $260 / 3397(7.7)$ & $223 / 2086(10.7)$ \\
\hline Smoking & $563 / 2420(23.3)$ & $410 / 1959(20.9)$ & $973 / 4379(22.2)$ & $632 / 2707(23.3)$ \\
\hline Coronary artery disease & $144 / 1651(8.7)$ & $243 / 1735(14.0)$ & $387 / 3386(11.4)$ & 190/1390 (13.7) \\
\hline Heart failure & $125 / 1651(7.6)$ & $82 / 1069(7.7)$ & $207 / 2720(7.6)$ & $60 / 1042(5.8)$ \\
\hline \multicolumn{5}{|c|}{ Medications } \\
\hline Antiplatelet & $531 / 2013(26.4)$ & $644 / 1901(33.9)$ & $1175 / 3914(30.0)$ & $487 / 1367(35.6)$ \\
\hline Anticoagulation & $179 / 2013(8.9)$ & $134 / 1285(10.4)$ & $313 / 3298(9.5)$ & 125/1131 (11.1) \\
\hline Statin & 296/2013 (14.7) & $174 / 1285(13.5)$ & $470 / 3298(14.3)$ & $188 / 1131(16.6)$ \\
\hline \multicolumn{5}{|c|}{ Clot Localisation } \\
\hline Left-hemispheric stroke & $343 / 598(57.4)$ & $109 / 221(49.3)$ & $452 / 819(55.2)$ & $641 / 1257(51.0)$ \\
\hline ICA & $587 / 2645(22.2)$ & $472 / 2216(21.3)$ & $1059 / 4861(21.8)$ & $543 / 3121(17.4)$ \\
\hline M1 & $1055 / 2645(39.9)$ & $1069 / 2216(48.2)$ & $2124 / 4861(43.7)$ & $1439 / 3121(46.1)$ \\
\hline M2 & $239 / 2570(9.3)$ & $294 / 2216(13.3)$ & $533 / 4786(11.1)$ & $343 / 3009(11.4)$ \\
\hline Tandem occlusion & $290 / 2189(13.2)$ & $253 / 1995(12.7)$ & $543 / 4184(13.0)$ & 229/1679 (13.6) \\
\hline Vertebrobasilar & $553 / 2100(26.3)$ & $98 / 1330(7.4)$ & $651 / 3430(19.0)$ & $142 / 1310(10.8)$ \\
\hline \multicolumn{5}{|c|}{ First-line EVT technique } \\
\hline SR & 969/1951 (49.7) & $690 / 1781(38.7)$ & $1659 / 3732(44.5)$ & $1131 / 2324(48.7)$ \\
\hline $\mathrm{CA}$ & $553 / 1599(34.6)$ & $504 / 1625(31.0)$ & $1057 / 3224(32.8)$ & $693 / 1618(42.8)$ \\
\hline Combined (SR \& CA) & 293/1487 (19.7) & $523 / 1625(32.2)$ & $816 / 3112(26.2)$ & $331 / 1547(21.4)$ \\
\hline
\end{tabular}

$\mathrm{LA}=$ local anaesthesia, $\mathrm{CS}=$ conscious sedation, $\mathrm{GA}=$ general anaesthesia, $\mathrm{EVT}=$ endovascular technique, NIHSS $=$ National Institutes of Health Stroke Scale, $\mathrm{mRS}=$ modified Rankin Scale, IV-tPA = intravenous tissue plasminogen activator, $\mathrm{ASPECTS}=$ Alberta stroke program early $\mathrm{CT}$ score, $\mathrm{HTN}=$ hypertension, $\mathrm{DM}=$ diabetes mellitus, $\mathrm{AF}=$ atrial fibrillation, $\mathrm{SR}=$ stentretriever, $\mathrm{CA}=$ contact aspiration,

Supplementary Figure 2: Population characteristics according to the anaesthetic regime. 
GA vs LA

Study or Subgroup log[Odds Ratio] SE Weight IV, Random, 95\% C

\begin{tabular}{lllll}
\hline Cappellari, 2020 & -0.2627 & 0.1564 & $29.5 \%$ & $0.77[0.57,1.04]$
\end{tabular}

Goldhoorn, $2020 \quad-0.2357 \quad 0.1577 \quad 29.4 \% \quad 0.79[0.58,1.08]$

$\begin{array}{lllll}\text { Pop, } 2020 & 0.6523 & 0.2983 & 17.9 \% & 1.92[1.07,3.45]\end{array}$

Wu, 2019

$\mathrm{Wu}, 2020$

$-0.22940 .3875$

$13.1 \%$

$0.80[0.37,1.70]$

Total $(95 \% \mathrm{Cl})$

$100.0 \% \quad 0.98[0.70,1.37]$

Heterogeneity: $\mathrm{Tau}^{2}=0.08 ; \mathrm{Chi}^{2}=9.26, \mathrm{df}=4(\mathrm{P}=0.05) ; \mathrm{I}^{2}=57 \%$

Test for overall effect: $Z=0.13(P=0.89)$

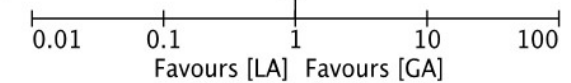

\section{CS vs LA}

\begin{tabular}{|c|c|c|c|c|c|c|c|c|}
\hline Study or Subgroup & log[Odds Ratio] & SE & Weight & $\begin{array}{c}\text { Odds Ratio } \\
\text { IV, Random, 95\% Cl }\end{array}$ & & & Ratio & \\
\hline Benvegnu, 2020 & 0.4947 & 0.1946 & $50.2 \%$ & $1.64[1.12,2.40]$ & & & & \\
\hline Goldhoorn, 2020 & -1.0498 & 0.2142 & $49.8 \%$ & $0.35[0.23,0.53]$ & & & & \\
\hline Total $(95 \% \mathrm{Cl})$ & & & $100.0 \%$ & $0.76[0.17,3.45]$ & & & & \\
\hline \multicolumn{5}{|c|}{$\begin{array}{l}\text { Heterogeneity: } \text { Tau }^{2}=1.15 ; \mathrm{Chi}^{2}=28.48, \mathrm{df}=1(\mathrm{P}<0.00001) ; \mathrm{I}^{2}=96 \% \\
\text { Test for overall effect: } Z=0.36(P=0.72)\end{array}$} & 0.01 & $\begin{array}{l}0.1 \\
\text { Fav }\end{array}$ & $\begin{array}{r}10 \\
\text { Favours [CS] }\end{array}$ & 100 \\
\hline
\end{tabular}

488 Supplementary Figure 3: Forest plot demonstrating the odds of a good functional outcome

$489(\mathrm{mRs} \leq 2)$ at 90 days between local anaesthesia (LA) and general anaesthesia (GA) or

490 conscious sedation (CS) using data adjusted for confounders. 
GA vs LA

Study or Subgroup log[Odds Ratio] SE Weight IV, Random, 95\% C

Odds Ratio

Cappellari, 2020

0.21110 .1942

$0.3293 \quad 0.168$

$32.8 \%$

$1.24[0.84,1.81]$

$-0.2614 \quad 0.3342$

0.55960 .6192

$1.39[1.00,1.93]$

Pop, 2020

$0.77[0.40,1.48]$

$\mathrm{Wu}, 2019$

$0.1249 \quad 0.3678$

$1.75[0.52,5.89]$

Wu, 2020

$100.0 \% \quad 1.24[1.00,1.54]$

Total $(95 \% \mathrm{Cl})$

Heterogeneity: $\mathrm{Tau}^{2}=0.00 ; \mathrm{Chi}^{2}=2.86, \mathrm{df}=4(\mathrm{P}=0.58) ; \mathrm{I}^{2}=0 \%$

Test for overall effect: $Z=1.92(P=0.05)$

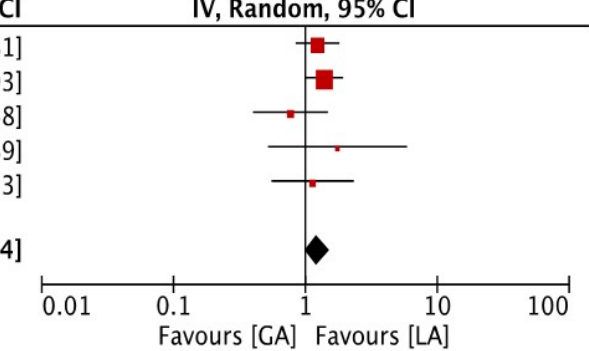

\section{CS vs LA}

Study or Subgroup log[Odds Ratio] SE Weight IV, Random, 95\% CI

$\begin{array}{lllll}\text { Benvegnu, } 2020 & -0.3857 & 0.2338 & 49.7 \% & 0.68[0.43,1.08\end{array}$

Coldhoorn, $2020 \quad 0.67290 .2174 \quad 50.3 \% \quad 1.96[1.28,3.00]$

Total $(95 \% \mathrm{Cl})$

$100.0 \% \quad 1.16[0.41,3.27]$

Heterogeneity: $\mathrm{Tau}^{2}=0.51 ; \mathrm{Chi}^{2}=10.99, \mathrm{df}=1(\mathrm{P}=0.0009) ; \mathrm{I}^{2}=91 \%$

Test for overall effect: $Z=0.28(P=0.78)$

Odds Ratio IV, Random, $95 \% \mathrm{Cl}$

499 Supplementary Figure 4: Forest plot demonstrating the odds of death at 90 days between

500 local anaesthesia (LA) and general anaesthesia (GA) or conscious sedation (CS) using data 501 adjusted for confounders. 
Risk of bias domains

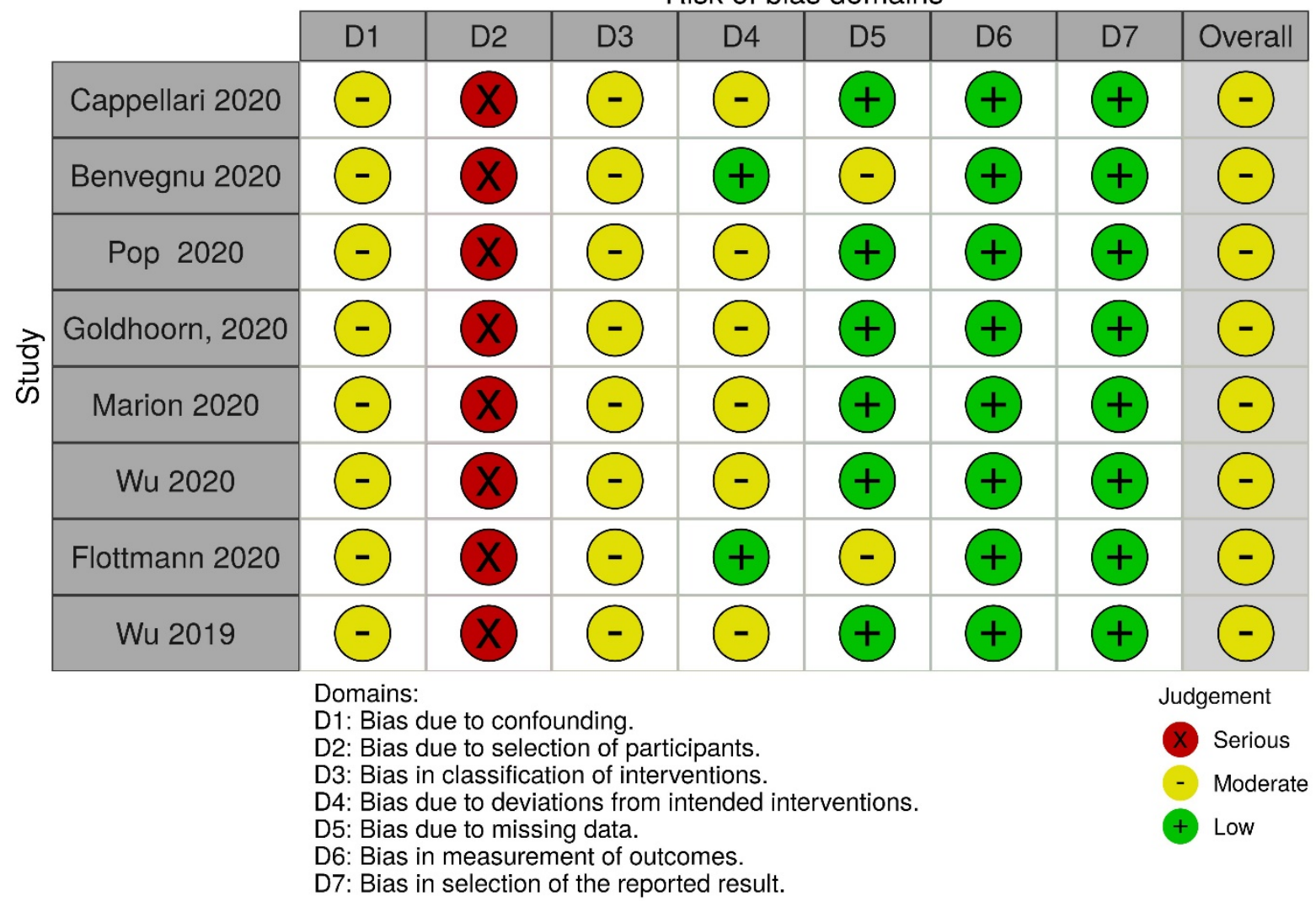

505 Supplementary Figure 5: Risk of bias assessment based on the ROBINS-I tool for non-

506 randomised studies. 
A. LA vs GA

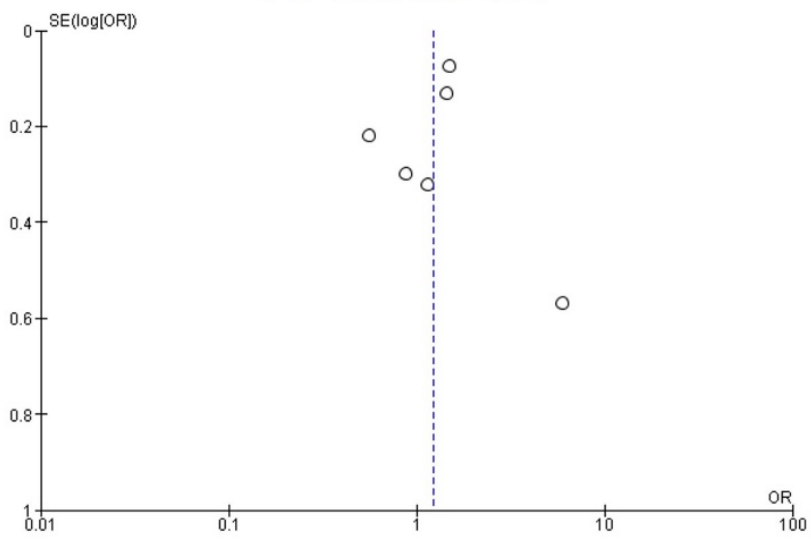

B. LA vs CS

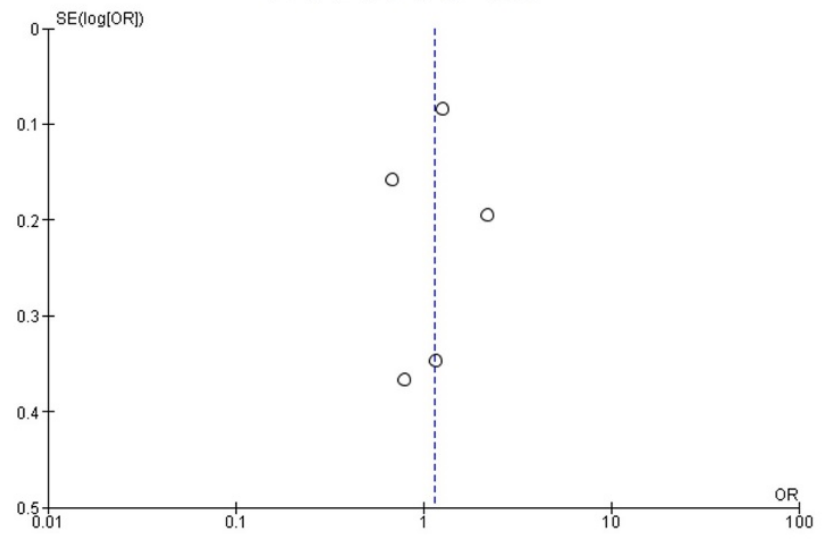

\section{LA vs GA+CS}

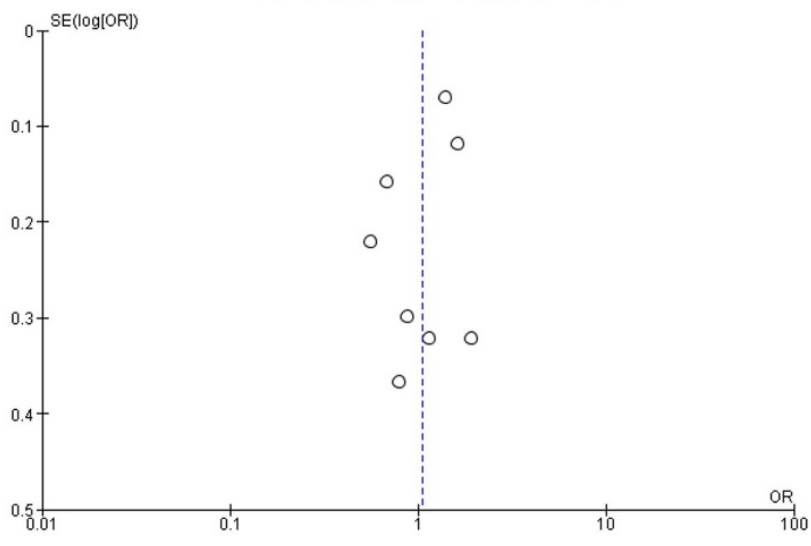

511 Supplementary Figure 6: Funnel plot for publication bias for good functional outcome

$512(\mathrm{mRs} \leq 2)$ at 90 days between local anaesthesia (LA) and general anaesthesia (GA) or

513 conscious sedation (CS). 